\title{
The Medical Management of Gastro-Oesophageal Reflux Disease
}

\author{
Neel Sharma Khek Yu Ho \\ Division of Gastroenterology and Hepatology, National University Hospital, Singapore
}

\author{
Key Words \\ Barrett's oesophagus - Gastro-oesophageal reflux disease · \\ Lifestyle interventions · Medical therapy · Oesophageal \\ adenocarcinoma
}

\begin{abstract}
Background: Gastro-oesophageal reflux disease (GORD) is a common global phenomenon. It is associated with the backflow of gastric contents proximally, typically due to transient relaxations of the lower oesophageal sphincter. Various factors contribute to GORD, including obesity, smoking, alcohol and pregnancy. The primary concern of GORD is its association with the development over time of Barrett's oesophagus and, ultimately, oesophageal adenocarcinoma. Summary: This review focuses on the various medical interventions that are useful in the treatment of GORD. Key Messages: Various lifestyle interventions such as weight loss and smoking cessation are useful in the treatment of GORD. Medical therapy relies on the use of acid suppressants such as proton pump inhibitors and histamine $\mathrm{H}_{2}$ receptor antagonists.
\end{abstract}

(c) 2016 S. Karger AG, Basel

\section{Introduction}

Gastro-oesophageal reflux disease (GORD) is rising in prevalence. Evidence suggests that chronic GORD is associated with the development of worsening inflamma-

\section{KARGER}

E-Mail karger@karger.com www.karger.com/iid tion, Barrett's oesophagus, dysplasia and, ultimately, adenocarcinoma. Survival of oesophageal adenocarcinoma is bleak with an estimated 5-year survival rate of $15 \%$. Hence, appropriate management of GORD is needed in order to hinder progression.

This review highlights the current evidence in reference to the medical management of GORD.

\section{Lifestyle Measures}

Initial management relies on lifestyle-based improvements including a focus on smoking and alcohol cessation, weight reduction, raising the head of the bed, reduction of eating meals late and reduction of foods that can primarily lead to enhanced reflux occurrence. These include coffee, chocolate, spiced, acidic and heavily fatty foods.

Kaltenbach et al. [1] screened 2,039 studies and identified trials that examined GORD in relation to lifestyle measures. Exposure to tobacco, alcohol, chocolate and high-fat meals decreased lower oesophageal sphincter pressure. However, neither tobacco nor alcohol cessation was associated with improvement in oesophageal $\mathrm{pH}$ or symptoms. Head of bed elevation and left lateral decubitus position improved the overall time that the oesophageal $\mathrm{pH}$ was $<4.0$. Weight loss improved oesophageal $\mathrm{pH}$ and symptoms.

Focusing on body mass index (BMI), Jacobson et al. [2] observed a relationship between increasing BMI and 
reflux symptoms in women (multivariate $\mathrm{p}$ for trend $<0.001)$. As compared to women who had a BMI of 20.022.4 , the multivariate odds ratios for frequent symptoms were 0.67 for a BMI of $<20.0 ; 2.20$ for a BMI of 25.0-27.4, and 2.93 for a BMI of 35.0 or more.

A further study focused on 24-hour $\mathrm{pH}$ measurements in morbid obesity, where 5 out of 17 patients had pathological acid reflux prior to weight loss. This was reversed to normal in 3 subjects but remained abnormal in 2 [3].

A study on posture noted the percentage of time during which oesophageal $\mathrm{pH}$ was $<5$, and the number of reflux episodes was decreased when patients were in a bed-up position as compared to sitting or lying. There was no significant difference when sitting and lying positions were compared. The results, however, suggested that in the bed-up position, patients will have an improvement in symptoms [4].

A further study compared the effect of three sleeping positions on gastro-oesophageal reflux: elevation of the head of the bed on 8-inch bed blocks; elevation by a foam wedge, or a flat position. No difference in reflux frequency between the positions was noted. The wedge caused a statistically significant decrease in the time that the distal oesophageal $\mathrm{pH}$ was $<4$ as compared to the flat position. Elevation on blocks caused an improvement in parameters, but this was not statistically significant [5].

\section{Pharmaceutical Management}

Cremonini et al. [6] undertook a meta-analysis which included more than 20 patients with GORD treated with either a proton pump inhibitor (PPI) or a histamine $\mathrm{H}_{2}$ receptor antagonist (H2RA) for at least 2 weeks. The odds ratio for response to active treatment compared to placebo was 3.71 (95\% CI 2.78-4.96).

Chiba et al. [7] reported that the overall healing proportion irrespective of drug dose or treatment duration ( $<12$ vs. 12 weeks) was highest with PPIs $(83.6 \pm 11.4 \%)$ compared to H2RAs (51.9 $\pm 17.1 \%)$, sucralfate (39.2 \pm $22.4 \%)$ or placebo $(28.2 \pm 15.6 \%)$. The mean heartburnfree proportion was highest with PPIs $(77.4 \pm 10.4 \%)$ compared to H2RAs (47.6 $\pm 15.5 \%)$. PPIs showed a significantly faster healing rate and provided faster heartburn relief.

A further study randomly assigned 247 patients with erosive oesophagitis to treatment with either $30 \mathrm{mg}$ lansoprazole once daily or $150 \mathrm{mg}$ ranitidine twice daily. Lansoprazole healed oesophagitis in $92.1 \%$ of patients after 8 weeks of treatment and was significantly superior to ranitidine which healed oesophagitis in $69.9 \%$ of patients $(\mathrm{p}<0.001)$ [8].

A double-blind controlled study randomly allocated patients to either omeprazole $40 \mathrm{mg}$ once daily or ranitidine $150 \mathrm{mg}$ twice daily. The healing rate after 4 weeks of treatment was $85 \%$ in those treated with omeprazole and $40 \%$ in those treated with ranitidine $(\mathrm{p}<0.001)$. Patients treated with omeprazole showed a significantly faster and greater relief in heartburn than patients treated with ranitidine [9].

Van Pinxteren et al. [10] noted that the relative risk (RR) for heartburn remission in placebo-controlled trials was 0.35 for PPIs (95\% CI 0.26-0.46), 0.77 for H2RAs (95\% CI $0.60-0.99)$ and 0.86 for prokinetics (95\% CI $0.73-1.01)$. PPIs were significantly ( $p<0.05)$ more effective than H2RAs and prokinetics. In the treatment of endoscopic negative reflux disease, the RR for heartburn remission was 0.68 for PPI compared to placebo and 0.84 for H2RA compared to placebo.

Gralnek et al. [11] noted that at 8 weeks, there was a $5 \%$ (RR 1.05; 95\% CI 1.02-1.08) relative increase in the probability of healing of erosive oesophagitis with esomeprazole, yielding an absolute risk reduction of $4 \%$. Esomeprazole conferred an 8\% (RR 1.08; 95\% CI 1.051.11) relative increase in the probability of GORD symptom relief at 4 weeks.

Gerson et al. [12] analysed omeprazole sodium bicarbonate therapy twice daily and noted normalisation of supine $\mathrm{pH}$ in $100 \%$ of patients.

Additional research analysed patients receiving dexlansoprazole MR 60 or $90 \mathrm{mg}$ or lansoprazole $30 \mathrm{mg}$ once daily. Dexlansoprazole MR healed $92-95 \%$ of patients, while lansoprazole healed $86-92 \%$ of patients ( $p>0.025)$. Week- 4 healing was greater than $64 \%$ with all treatments. An analysis of 8-week healing of patients with moderateto-severe oesophagitis demonstrated that dexlansoprazole MR $90 \mathrm{mg}$ was superior to lansoprazole. All treatments effectively relieved symptoms and were well tolerated [13].

Lee et al. [14] performed a randomised study of 48 healthy subjects who received dexlansoprazole MR $60 \mathrm{mg}$ once daily $30 \mathrm{~min}$ before meals. The results revealed no statistically significant differences in the mean 24-hour intragastric $\mathrm{pH}$ between dosing before dinner or an evening snack compared to breakfast; however, there was a small (0.2) but statistically significant difference between lunch and breakfast.

Gunaratnam et al. [15] assessed optimal PPI dosing and noted that optimal dosers took PPIs with or up to 60 min before meals. Their results highlighted that only $46 \%$ 
of patients dosed optimally. Fifty-four percent dosed suboptimally with 21 of 54 (39\%) dosing more than $60 \mathrm{~min}$ before meals.

A multicentre double-blind trial randomised patients to treatment for 8 weeks with either single-dose esomeprazole (40 mg once daily; $\mathrm{n}=138$ ) or lansoprazole $30 \mathrm{mg}$ twice daily $(\mathrm{n}=144)$. The findings highlighted that single-dose esomeprazole was at least as effective as twicedaily lansoprazole for the percentage of heartburn-free days (54.4 and 57.5\%, respectively) [16].

In a trial focused on maintenance therapies for reflux oesophagitis, the study groups were treated with cisapride (10 mg 3 times a day), ranitidine (150 mg 3 times a day), omeprazole (20 mg per day), ranitidine plus cisapride or omeprazole plus cisapride. The study highlighted that omeprazole was significantly more effective than cisapride $(\mathrm{p}=0.02)$ or ranitidine $(\mathrm{p}=0.003)$, and combination therapy with omeprazole plus cisapride was significantly more effective than cisapride alone $(p=0.003)$, ranitidine alone $(\mathrm{p}<0.001)$ or ranitidine plus cisapride $(\mathrm{p}=0.03)[17]$.

The efficacy of on-demand treatment with omeprazole 20 or $10 \mathrm{mg}$ or placebo has also been analysed. Results revealed that after 6 months, the remission rates were $83 \%$ (95\% CI 77-89) with omeprazole $20 \mathrm{mg}, 69 \%$ (95\% CI 61-77) with omeprazole $10 \mathrm{mg}$ and 56\% (95\% CI 4664 ) with placebo ( $p<0.01$ for all intergroup differences). The use of antacids proved highest in the placebo group and lowest in the omeprazole $20 \mathrm{mg}$ group. Treatment failure was associated with more than a doubling of antacid use [18].

Step-down management of GORD has been investigated. Forty-one of 71 patients (58\%) were asymptomatic off PPI therapy after 1 year of follow-up. Twenty-four of 71 patients (34\%) required H2RAs, 5 of 71 patients (7\%) required prokinetic agents and 11 of 71 patients (15\%) remained asymptomatic without medication [19].

Fackler et al. [20] analysed 23 healthy volunteers and 20 GORD patients. The administration of PPI and 1 day of H2RA was the only therapy that significantly decreased gastric $\mathrm{pH}<4$ compared to PPI twice daily alone ( $\mathrm{p}<$ $0.001)$.

Richter et al. [21] randomised patients to omeprazole $20 \mathrm{mg}$ once daily, ranitidine hydrochloride $(\mathrm{HCl}) 150 \mathrm{mg}$ twice daily or ranitidine $\mathrm{HCl} 150 \mathrm{mg}$ twice daily plus metoclopramide $\mathrm{HCl} 10 \mathrm{mg} 4$ times daily. After 1 week, $13 \%$ of patients receiving omeprazole had complete resolution of all GORD symptoms compared to 1 or $3 \%$ of patients receiving ranitidine or ranitidine/metoclopramide, respectively $(\mathrm{p}<0.001)$. At week $8,80 \%$ of pa- tients with oesophagitis grade 2 or higher were healed with omeprazole $[\mathrm{p}<0.001$ vs. ranitidine $(40 \%)$ and ranitidine/metoclopramide (46\%)].

A double-blind study used metoclopramide $10 \mathrm{mg} 4$ times daily, domperidone $20 \mathrm{mg} 4$ times daily or placebo randomly. As a whole, the treatment showed a significant symptomatic response in all three treatment groups $(\mathrm{p}<$ 0.0001 ). Eleven patients complained of side effects with metoclopramide. Two patients described side effects with domperidone, including 1 woman with galactorrhoea [22].

Grossi et al. [23] investigated oesophageal motility in GORD patients $24 \mathrm{~h}$ before and after the administration of baclofen. Baclofen increased the basal tone of the lower oesophageal sphincter in comparison with baseline $(\mathrm{p}=0.02)$, with a reduction in the number of transient lower oesophageal sphincter relaxations $(\mathrm{p}=0.01)$. Furthermore, baclofen induced a decrease in the swallows $(\mathrm{p}=0.02)$ and primary oesophageal body waves $(\mathrm{p}=$ $0.04)$.

A further study of patients with persistent heartburn or regurgitation in spite of PPI therapy concluded that after addition of baclofen $20 \mathrm{mg} 3$ times daily, duodenal reflux had significantly decreased [6.1\% (interquartile range $0.8 ; 10.3$ ) of the time; $\mathrm{p}<0.05$ ] [24].

More evidence comes from Cange et al. [25] who studied 20 patients with established reflux disease. Baclofen $40 \mathrm{mg}$ or placebo was given with a washout period of 4 weeks. The results showed a significant reduction in the number of reflux episodes during the 0 - to 4 -hour ( 7.9 vs. $16.5, \mathrm{p}<0.0001$; post-prandially: 6.0 vs. $11.2, \mathrm{p}<0.0001)$ and 0 - to 12 -hour ( 46.5 vs. $73, \mathrm{p}=0.0001$; post-prandially: 18.8 vs. $29.3, \mathrm{p}<0.0001)$ periods.

\section{Closing Remarks and Summary}

- Lifestyle intervention is paramount with a focus on weight loss and avoidance of reflux-triggering foods.

- PPI therapy is the treatment of choice before meals, initially once daily and increased to twice daily as required.

- H2RAs are add-on treatments to the use of PPIs.

- Currently, baclofen is not approved for the treatment of GORD, and research continues in this regard.

\section{Disclosure Statement}

The authors report that they have no conflicts of interest.
Sharma/Ho 


\section{References}

$>1$ Kaltenbach T, Crockett S, Gerson LB: Are lifestyle measures effective in patients with gastroesophageal reflux disease? An evidencebased approach. Arch Intern Med 2006;166: 965-971.

$>2$ Jacobson BC, Somers SC, Fuchs CS, Kelly CP, Camargo CA: Body-mass index and symptoms of gastroesophageal reflux in women. $\mathrm{N}$ Engl J Med 2006;354:2340-2348.

-3 Mathus-Vliegen LM, Tytgat GN: Twentyfour-hour $\mathrm{pH}$ measurements in morbid obesity: effects of massive overweight, weight loss and gastric distension. Eur J Gastroenterol Hepatol 1996;8:635-640.

4 Stanciu C, Bennett JR: Effects of posture on gastro-oesophageal reflux. Digestion 1977;15: 104-109.

$\checkmark 5$ Hamilton JW, Boisen RJ, Yamamoto DT, Wagner JL, Reichelderfer M: Sleeping on a wedge diminishes exposure of the esophagus to refluxed acid. Dig Dis Sci 1988;33:518-522.

$\checkmark 6$ Cremonini F, Ziogas DC, Chang HY, Kokkotou E, Kelley JM, Conboy L, Lembo AJ: Meta-analysis: the effects of placebo treatment on gastro-oesophageal reflux disease. Aliment Pharmacol Ther 2010;32:29-42.

7 Chiba N, De Gara CJ, Wilkinson JM, Hunt $\mathrm{RH}$ : Speed of healing and symptom relief in grade II to IV gastroesophageal reflux disease: a meta-analysis. Gastroenterology 1997;112: 1798-1810.

$>8$ Robinson M, Sahba B, Avner D, Jhala N, Greski-Rose PA, Jennings DE: A comparison of lansoprazole and ranitidine in the treatment of erosive oesophagitis. Multicentre Investigational Group. Aliment Pharmacol Ther 1995;9:25-31.

$>9$ Vantrappen G, Rutgeerts L, Schurmans P, Coenegrachts JL: Omeprazole (40 mg) is superior to ranitidine in short-term treatment of ulcerative reflux esophagitis. Dig Dis Sci 1988;33:523-529.
10 van Pinxteren B, Numans ME, Bonis PA, Lau $\mathrm{J}$ : Short-term treatment with proton pump inhibitors, $\mathrm{H}_{2}$-receptor antagonists and prokinetics for gastro-oesophageal reflux diseaselike symptoms and endoscopy negative reflux disease. Cochrane Database Syst Rev 2006;(3):CD002095.

11 Gralnek IM, Dulai GS, Fennerty MB, Spiegel BM: Esomeprazole versus other proton pump inhibitors in erosive esophagitis: a meta-analysis of randomized clinical trials. Clin Gastroenterol Hepatol 2006;4:1452-1458.

12 Gerson LB, Mitra S, Bleker WF, Yeung P: Control of intra-oesophageal $\mathrm{pH}$ in patients with Barrett's oesophagus on omeprazole-sodium bicarbonate therapy. Aliment Pharmacol Ther 2012;35:803-809.

13 Sharma P, Shaheen NJ, Perez MC, Pilmer BL, Lee M, Atkinson SN, Peura D: Clinical trials: healing of erosive oesophagitis with dexlansoprazole MR, a proton pump inhibitor with a novel dual delayed-release formulation - results from two randomized controlled studies. Aliment Pharmacol Ther 2009;29:731741.

14 Lee RD, Mulford D, Wu J, Atkinson SN: The effect of time-of-day dosing on the pharmacokinetics and pharmacodynamics of dexlansoprazole MR: evidence for dosing flexibility with a dual delayed release proton pump inhibitor. Aliment Pharmacol Ther 2010;31: 1001-1011.

15 Gunaratnam NT, Jessup TP, Inadomi J, Lascewski DP: Sub-optimal proton pump inhibitor dosing is prevalent in patients with poorly controlled gastro-oesophageal reflux disease. Aliment Pharmacol Ther 2006;23:1473-1477.

16 Fass R, Sontag SJ, Traxler B, Sostek M: Treatment of patients with persistent heartburn symptoms: a double-blind, randomized trial. Clin Gastroenterol Hepatol 2006;4:50-56.

17 Vigneri S, Termini R, Leandro G, Badalamenti S, Pantalena M, Savarino V, Davi G: A comparison of five maintenance therapies for reflux esophagitis. N Engl J Med 1995;333: 1106-1110.
18 Lind T, Havelund T, Lundell L, Glise H, Lauritsen K, Pedersen SA, Junghard O: On demand therapy with omeprazole for the longterm management of patients with heartburn without oesophagitis - a placebo-controlled randomized trial. Aliment Pharmacol Ther 1999;13:907-914.

19 Inadomi JM, Jamal R, Murata GH, Hoffman RM, Lavezo LA, Vigil JM, Sonnenberg A: Step-down management of gastroesophageal reflux disease. Gastroenterology 2001;121: 1095-1100.

20 Fackler WK, Ours TM, Vaezi MF, Richter JE: Long-term effect of H2RA therapy on nocturnal gastric acid breakthrough. Gastroenterology 2002;122:625-632.

21 Richter JE, Sabesin SM, Kogut DG, Kerr RM, Wruble LD, Collen MJ: Omeprazole versus ranitidine or ranitidine/metoclopramide in poorly responsive symptomatic gastroesophageal reflux disease. Am J Gastroenterol 1996; 91:1766-1772.

22 Maddern GJ, Kiroff GK, Leppard PI, Jamieson GG: Domperidone, metoclopramide, and placebo. All give symptomatic improvement in gastroesophageal reflux. J Clin Gastroenterol 1986;8:135-140.

23 Grossi L, Spezzaferro M, Sacco LF, Marzio L: Effect of baclofen on oesophageal motility and transient lower oesophageal sphincter relaxations in GORD patients: a 48-h manometric study. Neurogastroenterol Motil 2008;20: 760-766.

24 Koek GH, Sifrim D, Lerut T, Janssens J, Tack J: Effect of the GABA(B) agonist baclofen in patients with symptoms and duodeno-gastrooesophageal reflux refractory to proton pump inhibitors. Gut 2003;52:1397-1402.

25 Cange L, Johnsson E, Rydholm H, Lehmann A, Finizia C, Lundell L, Ruth M: Baclofen-mediated gastro-oesophageal acid reflux control in patients with established reflux disease. Aliment Pharmacol Ther 2002;16:869-873. 